hopeless task. Until 1982, when I met Piotr Kapitza who worked in Cambridge with Dirac, his close friend, at the Rutherford Laboratory.

After the discovery of the Dirac equation, at every seminar no matter the topic, someone - often myself, Piotr Kapitza told me - asked: "Dirac, where is the antielectron?". Needless to say, a chorus of laughs closed the seminar.

Paul Dirac eventually had had enough and decided to stop this. He knew that few colleagues were able to follow his arguments, and that even fewer had seriously studied his equation. Wanting to fool all these people, Dirac announced: "The proton has the opposite charge to that of the electron.
So let us take the proton as a good candidate for being the antielectron." And so he started spreading the rumour that he was seriously considering the proton as the antiparticle predicted by his equation. As for its mass, this was a detail that he was studying. Laughing at the end of each seminar stopped as soon as the rumour circulated. No one any longer asked the question, "Dirac, where is the antielectron?".

It was great to hear the story told by Piotr Kapitza, with his humour and ability. Paul Dirac was present and was laughing at Kapitza recollecting the fine hours in Cambridge.

Books carrying Pauli's remarks should perhaps be amended.

\title{
IOM Delegates to Council
}

The two new delegates of the Individual Ordinary Members to EPS Council, elected following the recent postal ballot, are:

M. Balkanski, Paris (F)

J. Fischer, Prague (CZ)

The delegates remaining in office are:

G. Chiarotti, Rome (I)

P. Choquard, Lausanne $(\mathrm{CH})$

F. Netter, Paris (F)

H. Ryde, Lund (S)

E. Skrzypczak, Warsaw (PL)

D. Stacey, Oxford, (UK)

W.T. Wenckebach, Leiden (NL)

Professor Minko Balkanski is with the Solid State Physics Laboratory, P. and M. Curie University, 4, Place Jussieu, Tour 13, F-75230 Paris Cedex 05. A French citizen born in 1927, he has worked as a Research Fellow at the Fritz Haber Institute in Berlin. A former Director of the Laboratory and a former Chairman of CMD, he remains a member of MIT's Advanced Study Institute.

Dr. Jan Fischer is a senior scientist at the Institute of Physics, Czechoslovak Academy of Sciences, Na Slovance 2, CS-180 40 Prague 8. A Czech citizen born in 1932, he has Doctorates from both the Institute and from Charles University, Prague. He has worked as a visiting scientist at JINR (Dubna), ICTP (Trieste) and CERN; and as a visiting professor at the University of Languedoc, Montpellier. Chief Editor of the Czechoslovak Journal of Physics, he has been an IOM Delegate to Council and is a Member of the HEPP Board.

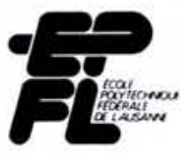

\section{Scientific Collaborators}

The Institute of micro- and opto-electronics of the Swiss Federal Institute of Technology is seeking applications for limited time research positions in the areas of device physics and the properties of heterojunction field effect transistors.

The positions would be suitable for candidates seeking to start a doctoral research program or for recently graduated scientists.

Candidates are asked to apply to:
Prof. M. llegems
Institut de Micro- et Opto- électronique
EPFL
$\mathrm{CH}-1015$ Lausanne
Switzerland

\section{Meeting Announcement}

10-12 Sept. 1991 Lund, Sweden

Nuclear Physics at Storage Rings: Disassembly of Nuclei and Subthreshold Meson Emission

P. Arve, Dept. of Mathematical Physics, Lund Institute of Technology,

POB 118, S-22100 Lund

POB 118, S-22100 Lund
++46 (46) $109090 / 104416$ matfys@ seldc52

\section{Board Changes}

Dr. Thomas Jarlborg has replaced Professor Jean Muller on the Editorial Board of Europhysics News. Swedish and a graduate of Chalmers University, Göteborg, he is an Associate Professor at the Department of Physics of Condensed Matter, University of Geneva where he has worked in the computational group for eight years. Prior to this he spent three years as a postdoc at Northwestern University in the USA. A theoretical solid state physicist, his main research interests involve the application of local density methods to the calculation of electromagnetic properties.

The Executive Committee of EPS has also approved the appointment of Dr. Fredrick James as the next Chairman of the Editorial Board of Europhysics News. An experimental physicist at CERN with a strong interest in data treatment, he is well known to us all as a former Chairman of the Computational Physics Group, and for his activities in connection with the academic freedom of physicists. Dr. James has been on the Board since 1986.

\section{Quantum Electronics Division}

From 1 April 1990, following elections in March, the Board of the Quantum Electronics Division will comprise the members listed below.

\section{Chairman: P.L. Knight, Imperial College, London}

Secretary: J.P. Woerdman, Univ., Leiden

Members:

J.S. Bakos, Central Research Institute, Budapest

R. Bonifacio, Univ., Milan

E. Giacobino, Univ., Paris

E.O. Goebel, Univ., Marburg

D.R. Hall, Heriot-Watt Univ, Edinburgh

J. Mlynek, Univ., Konstanz

O. Poulsen, Univ., Aarhus

F. Pradere, Ecole Poly., Palaiseau

F.K. Rheinhart, EPFL, Lausanne

S. Svanberg, Lund Inst. of Tech.

The Chairman, who took office last October, reports that the Division's main activity involves the organization of the International Quantum Electro- nics Conferences through the International Council of Quantum Electronics.

The 2nd European Quantum Electronics Conference (EOEC 89), which served as the Divisional meeting, was held on 28 August-1 September 1989 in Dresden. The next EQEC will be held in Edinburgh in September 1991.

\section{Environmental Physics Group}

Strong encouragement is emerging for The Institute of Physics plan to form an Environmental Physics Group whose aim is to promote physics within the context of environmental sciences. Support from anyone interested in the Group is welcome as a main objective is liaison with counterparts elsewhere in Europe and further afield. For information, contact Susanna Lithiby, IOP, 47 Belgrave Sq., London SW1X 8QX, Tel.: ++44-71-235 6111 ; Fax: $++44-71-2596002$. 